
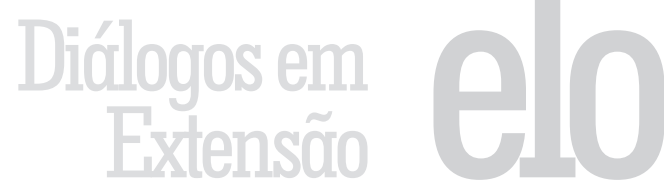

\title{
Economia solidária e o papel das incubadoras tecnológicas de cooperativas populares no Brasil: a experiência de extensão universitária da ITCP-UFV
}

Bianca Aparecida Lima Costa ${ }^{1}$

\begin{abstract}
Resumo: As Incubadoras Tecnológicas de Cooperativas Populares têm crescido no Brasil e desempenhado um papel importante no contexto da economia solidária, especialmente no apoio e fomento aos empreendimentos econômicos solidários de diferentes segmentos. Boa parte dessas experiências vincula-se a universidades públicas, atuando no campo da extensão e da pesquisa. O objetivo desse artigo é analisar a contribuição das ITCPs para a conformação da economia solidária no país, verificando de forma mais direta as ações do programa de extensão da Universidade Federal de Viçosa. A ITCP-UFV foi fundada em 2003 $e$, ao longo de sua trajetória, executou diversos projetos e programas, contribuindo para o desenvolvimento da economia solidária na Zona da Mata Mineira. Os procedimentos metodológicos adotados na pesquisa compreendem a revisão bibliográfica sobre o tema e o estudo de caso apoiado em pesquisa documental.
\end{abstract}

Palavras chave: Economia Solidária, extensão universitária, Incubadora Tecnológica de Cooperativas Populares, metodologia de incubação.

Áreas temáticas: Metodologias em extensão, tecnologia, teorias e trabalho.

\section{Solidarity economy and the role of technological incubators of popular cooperatives in Brazil: the experience of university extension at ITCP-UFV}

Abstract: The Technological Incubators of Popular Cooperatives have grown in Brazil and played an important role in the context of social economy, especially in supporting and fostering the solidarity economic enterprises of different segments. Much of this experience is linked to the public universities, working in the field of extension and research. The aim of this paper is to analyze the contribution of ITCPs for conformation of the solidarity economy in the country, checking in more direct actions of the outreach program of the Federal University of Viçosa. The ITCP - UFV was founded in 2003 and throughout his career has performed several projects and programs, contributing to the development of social economy in the Zona da Mata Mineira. The methodological procedures used in the research include literature review on the topic and case study supported by documentary research.

Keywords: Economic development, methodology incubation, Technological Incubator of Popular Cooperatives, university extension. 


\section{Economía solidaria y el papel de incubadoras tecnológicas de cooperativas populares en Brasil: la experiencia de la extensión universitaria de ITCP-UFV}

Resumen: Las Incubadoras Tecnológicas de Cooperativas Populares han crecido en Brasil y jugó un papel importante en el contexto de la economía social, especialmente en el apoyo y el fomento de las empresas económicas de solidaridad de diferentes segmentos. Gran parte de esta experiencia está vinculada a las universidades públicas, que trabajan en el campo de la extensión y la investigación. El objetivo de este trabajo es analizar la contribución del ITCP para la conformación de la economía solidaria en el país, el control de las acciones más directas del programa de extensión de la Universidad Federal de Viçosa. La ITCP-UFV fue fundada en 2003 ya lo largo de su carrera ha realizado diversos proyectos y programas, contribuyendo al desarrollo de la economía social en la Zona da Mata de Minería. Los procedimientos metodológicos utilizados en la investigación incluyen la revisión de la literatura sobre el tema de estudio y la caja con el apoyo de la investigación documental.

Palabras clave: Desarrollo económico, extensión universitaria, incubación metodología, Incubadora Tecnológica de Cooperativas Populares.

\section{Introdução}

O tema da economia solidária ganhou visibilidade significativa no Brasil, fundamentalmente na última década. Um conjunto expressivo de estudos e de pesquisas direciona-se à temática, assim como múltiplas iniciativas do campo da extensão universitária são desenvolvidas em todo o país. O número de Incubadoras Tecnológicas de Cooperativas Populares, assim como de projetos semelhantes cresceu apoiado por políticas de fomento de instituições públicas. Sem dúvida, tal perspectiva ganhou espaço considerável em boa parte das universidades públicas brasileiras que têm desempenhado papéis importantes na consolidação de empreendimentos econômicos solidários. Este crescimento, no entanto, não ocorre isoladamente. É possível afirmar que as Incubadoras fazem parte de um grupo de organizações que busca o fortalecimento da economia solidária em todo o território brasileiro. Nesse contexto, podem-se destacar as políticas públicas em nível federal desenvolvidas, desde 2003, pela Secretaria Nacional de Economia Solidária e as ações encampadas pelo Fórum Brasileiro de Economia Solidária, no qual as ITCPs têm participação significativa.

No geral, as ações das Incubadoras estão inscritas nos campos da extensão universitária e da pesquisa. Tais iniciativas tiveram início no fim da década de 1990, com uma expansão importante nos anos 2000. Essas experiências buscam desenvolver e consolidar metodologias de apoio e fomento aos grupos populares e solidários voltados à geração de trabalho e renda, assim como inclusão social através da autogestão. Trata-se da possibilidade de diálogo com populações, em geral, distantes dos ambientes acadêmicos. Apesar de justificável e claro, o desenvolvimento 
dessas atividades é difícil, por elas serem complexas e envolverem diferentes atores sociais em disputa pelos diversos modelos de "universidade" no Brasil. As ações direcionadas à economia solidária pressupõem a extensão dialógica e participativa, o que, na prática, representam desafios de diversos níveis.

Nesse contexto, ao compreender a importância dessa temática, o objetivo desse artigo é analisar o papel e a contribuição das ITCPs para a economia solidária no Brasil, verificando de forma mais direta as ações do programa de extensão da Incubadora Tecnológica de Cooperativas Populares da Universidade Federal de Viçosa. A ITCP-UFV foi fundada em 2003 e, ao longo de sua trajetória, executou diversos projetos e programas, contribuindo de forma fundamental para o desenvolvimento da economia solidária na Zona da Mata Mineira, por meio da incubação de grupos em diferentes segmentos econômicos e a participação no Fórum Regional e Mineiro de Economia Popular Solidária. Os procedimentos metodológicos adotados na pesquisa compreendem a revisão bibliográfica sobre o tema e o estudo de caso da ITCP-UFV apoiado em pesquisa documental.

O artigo está divido em três seções que tratam, num primeiro momento, do conceito de economia solidária, fundamentalmente a partir da realidade latinoamericana. Em seguida, são apresentados os principais atores sociais envolvidos na conformação da temática no país, analisando de forma específica as Incubadoras. Por fim, será analisada a trajetória da ITCP-UFV, ressaltando seu método de trabalho e os desafios que se colocam à sua ação na atualidade.

\section{O conceito de economia solidária no contexto latinoamericano}

Os debates sobre economia solidária iniciaram-se na década de 1990 em contextos sociais e econômicos diversos e alcançaram visibilidade principalmente no início dos anos 2000. O tema adquiriu força em ambientes acadêmicos direcionados à pesquisa, à produção teórica, à extensão universitária e também em espaços da sociedade civil e dos movimentos sociais. Embora os conceitos sobre este fenômeno não sejam consensuais, as circunstâncias de seu surgimento apresentam algumas convergências. É possível afirmar que mudanças no capitalismo mundial contribuíram para reativação das discussões sobre formas alternativas de desenvolvimento (SANTOS \& RODRÍGUEZ, 2002; LAVILLE, 2006; SINGER, 2003a; FRANÇA FILHO, 2006; QUIJANO, 2002).

No início do século XXI, movimentos sociais e entidades da sociedade civil mobilizaram-se sob o lema "outro mundo é possível". Vários autores identificam o Fórum Social Mundial - FSM como um dos principais espaços de fortalecimento da ideia de uma globalização alternativa ou solidária. A 
primeira edição do evento ocorreu em 2001, na cidade de Porto Alegre, Brasil (CORAGGIO, 2007; GAIGER, 2007; VIVERET, 2009, LAVILLE, 2006, LÉVESQUE, 2009; SANTOS; RODRIGUEZ, 2002; LIMA, 2009). O FSM é uma contraposição ao Fórum Econômico Mundial e envolve, de maneira voluntária e pluralista, atores sociais implicados na construção de uma sociedade mais justa e sustentável (SANTOS; RODRÍGUEZ, 2002; VIVERET, 2009).

Em vários países, a trajetória de ampliação da economia solidária está ligada à mobilização de organizações da sociedade civil e à implementação de políticas públicas com esta temática. Embora os formatos e preceitos sejam variados, a tentativa de vincular economia e democracia está presente em realidades diversas.

Os debates sobre economia solidária na América Latina, mesmo compartilhando semelhanças com processos de outros continentes, apresentam especificidades importantes em seu quadro analítico e teórico. A análise da abordagem latinoamericana deve privilegiar interpretações que observem o contexto histórico e sociocultural do continente, conforme ressaltam diversos estudiosos (SANTOS \& RODRÍGUEZ, 2002; CUNHA; SANTOS, 2011; CORAGGIO, 2007).Embora existam diferentes abordagens, pode-se afirmar que a perspectiva da economia solidária está relacionada ao caráter ideológico de mudança da sociedade. O foco principal do debate é a superação de formas desiguais de produção e distribuição de riquezas características do capitalismo hegemônico e neoliberal (SANTOS \& RODRÍGUEZ, 2002). As interpretações acerca dessas experiências na América Latina estão geralmente vinculadas às correntes teóricas de matriz crítica e dos pensamentos emancipatórios que compreendem a formulação de sistemas de produção alternativos em contraposição ao capitalismo (QUIJANO, 2002, p.478).

De acordo com Pochmann (2004), a América Latina enfrentou no último quarto do século XX uma das maiores crises de desenvolvimento, com falta de crescimento da renda per capita, instabilidade nas atividades produtivas, aprofundamento da financeirização das riquezas e a ampliação da inserção subordinada e passiva dos produtos latinoamericanos primários na economia mundial. O arranjo das economias capitalistas periféricas se caracterizava pela permanência de grande parte da população em condições precárias de vida e de trabalho.

O segmento dito organizado do trabalho e os empregos assalariados diminuíram e o desemprego aberto avançou. As formas vulneráveis e precárias de emprego cresceram e o trabalho desprotegido deixou de ser transitório para se tornar permanente. Esta realidade contribuiu para a conformação de um conjunto da população socialmente excluído (POCHMANN, 2007; PINTO, 2006; QUIJANO, 2002). Além disso, a adoção das políticas neoliberais já na década de 1990, segundo Tiriba 
(2007), aprofundou ainda mais este cenário de crise. Tais dados vêm sofrendo alterações, principalmente no Brasil, com a queda da taxa de desemprego e o crescimento da formalização das relações de trabalho. No entanto, esta ainda é uma realidade que apresenta dimensões significativas no país.

Quijano (2002) destaca que os trabalhadores concentraram suas forças na sobrevivência, aumentando o que ficou amplamente conhecido como "informalidade". A predominância da economia popular, característica peculiar à América Latina, pode ser considerada como uma forma de resistência fundamental no enfrentamento destas desvantagens presentes no mercado de trabalho.Nesse sentido, parte considerável dos autores latinoamericanos encontrou na resistência presente na economia popular e no conjunto de trabalhadores excluídos socialmente, o substrato para as diversas elaborações acerca da economia solidária. É importante destacar, conforme afirma Coraggio (2007), que mesmo não havendo um consenso acerca das definições sobre economia solidária na América Latina, é possível reconhecer alguns pontos comuns das principais concepções do continente. Em geral, esta variedade de interpretações, além de estar fundamentada no pressuposto de mudança social, engloba formas microeconômicas de economias organizadas por trabalhadores que se associam para produzir ou comprar coletivamente, seja para prover trabalho e renda, melhorar o poder de negociação, acessar crédito, ou mesmo para uso de bens comunitários que melhorem condições ou meios de vida. Essas são formas que, em grande medida, ultrapassam a lógica do mercado.

Guardadas as especificidades entre as abordagens, é possível identificar duas vertentes predominantes nas reflexões latinoamericanas. A primeira é identificada pelo termo da economia solidária e tem a cooperativa como unidade central para organização dos trabalhadores em diferentes ramos ou setores da atividade econômica vinculada ao mercado. A diferenciação com o sistema capitalista está na autogestão dos trabalhadores, destacando-se as organizações coletivas. Enfatiza-se não só a lógica da cooperação, mas também a posse conjunta dos meios de produção e o princípio da democracia. O potencial alternativo das cooperativas é muitas vezes colocado em questão. Entretanto, para alguns autores em países latinoamericanos e em especial no Brasil, este potencial é uma convicção.

A segunda vertente tem como base as análises da economia popular em que as instituições de composição sejam heterogêneas, e seus formatos não estejam focados somente nas cooperativas. As unidades podem ser constituídas por pessoas que, em geral, mantêm relações "primárias" entre si em pequenos agrupamentos e vinculados à lógica comunitária (QUIJANO, 2002). 
O economista Paul Singer (2002; 2003a; 2007) é um dos mais conhecidos estudiosos sobre a economia solidária no Brasil, não só por seus trabalhos desenvolvidos desde a década de 1970, mas também por seu importante papel no movimento social e no Estado. Singer ocupa desde 2003 a coordenação da Secretaria Nacional de Economia Solidária do país.A argumentação do autor refere-se em grande medida às reflexões sobre os diferentes tipos de socialismos, sendo a economia solidária uma de suas possibilidades. Para tanto, ele discute a interação do princípio de unidade entre posse e uso dos meios de produção e distribuição com o princípio da socialização desses meios. E conclui que esse processo é intrínseco à luta dos trabalhadores contra o capitalismo.

Singer (2002) analisa as cooperativas nos primórdios do capitalismo e demonstra que elas tiveram forte afinidade com as classes trabalhadoras e se manifestaram como organizações de operários em resposta à pobreza e ao desemprego. As cooperativas deste período representavam uma tentativa de recuperação do trabalho e da autonomia econômica a partir de princípios como igualdade e democracia (SINGER, 2002, p. 83).

As experiências solidárias não se baseiam na separação entre trabalho e posse dos meios de produção, pois seu capital pertence aos trabalhadores. A propriedade da empresa é dividida igualmente para que todos tenham o mesmo poder de decisão sobre ela, administrada, em geral, por sócios eleitos por todos os membros. O autor considera a autogestão marca principal da economia solidária.

Segundo Singer (2007), a prática e a experiência dos trabalhadores na autogestão seriam o laboratório propício às transformações sociais. $\mathrm{O}$ surgimento e o fortalecimento deste movimento reforçam o poder de luta de todos os trabalhadores. Embora haja um destaque para as cooperativas como organizações típicas, Singer considera que as unidades de produção da economia solidária são variadas e podem compreender também associações, clubes de trocas, entre outros. Isso significa que essas experiências podem estar presentes em todos os campos de atividade econômica.

Como a unidade típica da economia solidária é a cooperativa de produção, o autor ressalta que os princípios organizativos que deveriam estar implicados nas iniciativas solidárias são: posse coletiva dos meios de produção; gestão democrática da empresa, por participação direta ou por representação; repartição da receita líquida entre os cooperadores por critérios aprovados; destinação do excedente anual também por critérios acertados entre todos os cooperadores.

Um dos pontos de debilidade da economia solidária é a atuação isolada dos empreendimentos solidários nos mercados dominados por empresas capitalistas. Sua fortaleza está no princípio de autogestão e na melhora nas condições de trabalho, mesmo quando essas são precárias. Para 
Singer (2003a, 2007), a organização de iniciativas da economia solidária pode representar o início de transformações locais, que mudam o relacionamento entre os cooperadores e destes com a família, vizinhos, autoridades públicas, religiosas, intelectuais, promovendo mudanças em níveis individuais e sociais. Para tanto, é necessário garantir certas estruturas para sua sustentação como financiamento, redes de comercialização, assessoria científica e técnica, formação contínua dos trabalhadores, normativa legal adequada, entre outros (SINGER, 2007).

\section{O caminho da economia solidária no Brasil: o papel das incubadoras tecnológicas de cooperativas populares}

A experiência brasileira de economia solidária ganhou visibilidade nos últimos anos devido à conformação do movimento social, à inserção da temática em políticas públicas do Governo Federal e à expressão social das iniciativas produtivas presentes em todo o país. Trata-se de uma trajetória que teve início na década de 1980 e que ganhou maior impulso a partir dos anos de 1990. O ano de 2003 foi um marco nessa história com a criação do Fórum Brasileiro de Economia Solidária - FBES e da Secretaria Nacional de Economia Solidária. Essas duas experiências, que envolveram tanto as organizações da sociedade civil como o poder público, são responsáveis, em grande medida, pelas características deste movimento no país.

Além da mobilização nacional, na mesma época, diferentes estados da federação desenvolveram ações de promoção da economia solidária através de políticas públicas, como o caso emblemático do Rio Grande do Sul, ou através da organização da sociedade civil, como o Fórum de Cooperativismo Popular do Rio de Janeiro. O Estado de Minas Gerais, com cerca de 20 milhões de habitantes e 853 municípios, também pode ser destacado neste cenário. As primeiras reflexões sobre o tema iniciaram-se em meados de 1990 por meio de fóruns temáticos nos quais participavam diferentes organizações, como entidades sindicais, religiosas e de orientação feminista. O estado mineiro foi o primeiro a ter uma legislação específica para o fomento à economia solidária, contando atualmente com o Conselho Estadual sobre essa temática. A Incubadora Tecnológica de Cooperativas Populares da Universidade Federal de Viçosa também faz parte dessa história. Fundada como programa de extensão universitária em 2003, a ITCP-UFV contribuiu para a conformação do movimento de economia solidária em Minas Gerais por meio de diferentes ações e ainda tem papel importante nesse cenário no Estado, conforme será analisado na última seção deste artigo.

Em relação a essa temática, outro debate importante compreende as interpretações, por vezes dicotômicas, entre "novo" e "velho" cooperativismo. O "novo" estaria vinculado às experiências consideradas alternativas solidárias ao capitalismo e o "velho" relacionado com setores mais 
tradicionais e incorporado ao mercado em grandes ramos, como o agropecuário. $\mathrm{Na}$ vertente do que poderia se denominar um cooperativismo renovado, Singer (2003a) destaca os processos de organização dos trabalhadores, no início da década de 1990, para formação de cooperativas em função da recuperação de empresas falidas. Essas iniciativas podem ser consideradas como as primeiras experiências de economia solidária baseadas na autogestão no Brasil (SINGER, 2003a).

De acordo com Lima (2009), o crescimento do cooperativismo ocorre nesse período a partir de dois propósitos antagônicos. Em virtude de mudanças na economia e do aumento do desemprego, as cooperativas passaram a ser vistas como alternativas à falta de emprego e, no campo empresarial, como forma de redução de custos. Essas experiências se multiplicaram com a organização dos trabalhadores para recuperação de fábricas em situação de falência, mas também com a precarização do trabalho através de ações dos próprios empresários.

Apoiando as ações dos trabalhadores a fim de garantir os postos de trabalho perdidos no fechamento das fábricas, diferentes sindicatos, com destaque para os da região do $\mathrm{ABC}$ em São Paulo, foram fundamentais para o auxílio dos operários na gestão e manutenção das empresas com administração autogestionária (ODA, 2003). Em 1994, foi criada oficialmente a Associação Nacional de Trabalhadores em Empresas Autogestionárias e de Participação Acionária - Anteag com objetivo de amparar milhares de trabalhadores em processos de organização de empresas autogestionárias. A autogestão é a marca da entidade que buscou se fortalecer com base no desenvolvimento de novos modelos de gestão e de relações de trabalho (NAKANO, 2003).

Parte dessas cooperativas era organizada para reduzir os custos do trabalho nas empresas. Como ressalta Lima (2009), experiências com cooperativas de colheita de laranja em São Paulo e cooperativas industriais no Ceará podem ser incluídas nesse modelo ilegítimo de solidariedade econômica. Em função disso, a atuação sindical foi e ainda é conflituosa em relação ao apoio ao cooperativismo.

Esses primeiros passos da economia solidária sob a perspectiva da autogestão, especialmente em centros urbanos, foram confusos, mas importantes para afirmação das diferenças do projeto de organização do trabalho que se buscava construir, mesmo que seus limites permaneçam até hoje tênues.

Na área rural, Singer (2003a) destaca o Movimento dos Trabalhadores Rurais Sem Terra (MST) como importante no processo de construção da economia solidária, a partir da luta contra a exclusão social e pela reforma agrária. Conforme descreve Ferreira (2003), a cooperação e o incentivo à construção de cooperativas de diversos setores nos assentamentos do 
MST são estratégias fundamentais do movimento. Embora essas experimentações tenham sido conflituosas, as formas coletivas de gestão de recursos dos trabalhadores permanecem vinculadas às iniciativas e projetos do movimento (FERREIRA, 2003, p.91).

No âmbito das discussões do movimento sindical, outra iniciativa de destaque que surgiu no fim da década de 1990 foi a Agência de Desenvolvimento Solidário (ADS) da Central Única dos Trabalhadores (CUT), em parceria com a Unitrabalho e o Dieese. Conforme Magalhães e Todeschini (2003), o projeto nasceu das reflexões sobre o sindicalismo e o papel da CUT frente ao grave desemprego e às mudanças no mundo do trabalho. A entidade realizou diversos debates internos quanto ao projeto político em relação à economia solidária e deliberou, no fim de 1999, a criação da Agência. A ADS contava com um escritório nacional e outros regionais que desenvolviam projetos de fomento, apoio e organização de empreendimentos econômicos solidários de diversos setores. Parte destas estruturas foi reorganizada em função da criação da Unisol Brasil em 2000, uma central de empreendimentos dentro do projeto da CUT para economia solidária.

Ainda no âmbito das entidades fomentadoras de empreendimentos, é importante destacar também a atuação da Cáritas, órgão do Conselho Nacional de Bispos do Brasil - CNBB, que, por meio dos Projetos Alternativos Comunitários - PACs, apoiou iniciativas variadas para sobrevivência de comunidades pobres de diversas partes do Brasil (SINGER, 2003a; GAIGER, 2003). Singer (2003a) cita outras organizações, assim como governos municipais, importantes nesse contexto, como o caso de Porto Alegre, Blumenau, Santo André e São Paulo.

Outro processo importante da sociedade civil que contribuiu para o aparecimento de iniciativas econômicas nos primeiros anos da trajetória da economia solidária no Brasil foi o movimento da Ação da Cidadania contra a Fome, a Miséria e pela Vida. Liderado pelo sociólogo Betinho, em 1992, a população brasileira foi mobilizada para doação de alimentos para um "Natal sem fome". A distribuição de alimentos já no ano seguinte foi percebida como limitada e o desenvolvimento de estratégias de geração de trabalho e renda se mostrou fundamental. Nesse processo, surgiram projetos que desencadearam a constituição da primeira Incubadora Tecnológica de Cooperativas Populares - ITCP na Universidade Federal do Rio de Janeiro, seguida de várias outras iniciativas com o mesmo caráter em outras universidades brasileiras (SINGER, 2003b).

Lima (2009) ressalta que a experiência no Rio de Janeiro, por meio do programa de extensão da COOPPE-UFRJ (Instituto Alberto Luiz Coimbra de Pós-Graduação e Pesquisa de Engenharia), para apoio à organização da Cooperativa dos Trabalhadores de Manguinhos, em 1995, configurou-se como uma das primeiras iniciativas do "novo" cooperativismo. A proposta, 
além de envolver parcerias institucionais e políticas, como a FINEP e a Fundação Banco do Brasil, influenciou a criação do Programa Nacional de Incubadora de Cooperativas - PRONINC. Os primeiros artigos teóricos sobre o tema da autogestão como possibilidade efetiva de emancipação do trabalhador surgiram nesse processo (LIMA, 2009).

O objetivo do programa das ITCPs é utilizar "[...] os recursos humanos e conhecimento da universidade na formação, qualificação e assessoria de trabalhadores para a construção de atividades autogestionárias, visando sua inclusão no mercado de trabalho" (GUIMARÃES, 2003, p.111). Tais projetos estão em consonância com o princípio de extensão das universidades brasileiras em projetos de intervenção voltados à geração de trabalho e renda. Já em 1998 foi constituída uma rede que atualmente congrega ITCPs de todo o Brasil. De acordo com Lima (2009), o número de incubadoras universitárias cresceu de forma significativa no país, chegando a 42 no ano de 2009. Muitas dessas iniciativas começaram a realizar trabalhos conjuntos com municípios, a partir de políticas públicas direcionadas à economia solidária.

Observa-se, portanto, que a conformação da economia solidária no Brasil contou com a participação de diferentes atores sociais, tais como: organizações não-governamentais; movimentos sociais; organizações com vinculações religiosas; governos municipais, estaduais, federal, assim como as Universidades. O papel da extensão universitária é importante nesse cenário, pois agrega alguns fatores fundamentais ao desenvolvimento da economia solidária. O primeiro deles compreende o comprometimento social e comunitário implícito na missão da Universidade brasileira. O segundo ponto engloba o potencial de desenvolvimento tecnológico e metodológico adequados ao fomento e apoio aos empreendimentos econômicos solidários por meio da ação integrada entre extensão e pesquisa. Por fim, é possível ressaltar a função de formação de profissionais preparados para atuarem com a temática da economia solidária, compreendendo suas especificidades e contribuindo para seu fortalecimento no país.

As ITCPs são iniciativas importantes nos debates teóricos e práticos para o desenvolvimento de experiências solidárias, fundamentalmente de bases populares. Tais trajetórias não são lineares e, atualmente, muitas mudanças ocorreram desde a fundação da primeira ITCP. Os debates metodológicos têm avançado, especialmente em relação às ações mais integradas, ou seja, envolvendo temas como desenvolvimento local, tecnologia social, finanças solidárias, moedas sociais, comunidades tradicionais etc. O programa da Incubadora Tecnológica de Cooperativas Populares da Universidade Federal de Viçosa também vivencia tais desafios, pontos que serão analisados na próxima seção. 


\section{A experiência da ITCP-UFV: 10 anos de extensão universitária de apoio e fomento aos empreendimentos econômicos solidários}

A Incubadora Tecnológica de Cooperativas Populares da Universidade Federal de Viçosa (ITCP-UFV) é um programa de extensão universitária constituído em 2003. A ITCP desenvolve ações direcionadas ao fortalecimento e fomento de empreendimentos econômicos organizados a partir dos princípios da Economia Solidária, por meio da atuação multidisciplinar de estudantes e professores de diversas áreas do conhecimento acadêmico. O objetivo geral do programa é apoiar iniciativas coletivas visando seu fortalecimento nos aspectos econômicos, organizativos e sociais. Busca-se a geração de trabalho e renda, a promoção do consumo consciente, do comércio justo, da segurança alimentar, da produção agroecológica e solidária e do desenvolvimento local sustentável.

O programa está em consonância com as principais finalidades da Universidade Federal de Viçosa, assim como com as diretrizes e pilares da universidade brasileira. Como programa de extensão, a ITCP-UFV vem recebendo financiamento de diversas fontes e tem como principal característica proporcionar ações integradas de: 1) extensão, por levar em conta a realização direta de atividades com grupos populares, 2) ensino, na medida em que é um ambiente propício para consolidação e prática dos conhecimentos apreendidos sob a supervisão de docentes orientadores, 3) pesquisa, por estar inserida em um campo de inovação social em que as atividades científicas sob tais perspectivas sejam fundamentais.

A Incubadora tem como finalidades, portanto: promover a formação de agentes da economia popular solidária na universidade, bem como na sociedade; valorizar a extensão universitária dialógica; construir e socializar novos conhecimentos e tecnologias sociais, instigando o debate e a compreensão de outras concepções de desenvolvimento, além de construir novos valores baseados nos princípios da economia solidária.

As atividades desenvolvidas pela ITCP abrangem diversas disciplinas, proporcionando um espaço importante de troca e de construção coletiva. A UFV é uma das poucas instituições de ensino superior do Brasil que oferece um Curso de Bacharelado em Cooperativismo. Isso contribui de maneira fundamental para os trabalhos da ITCP que também conta com alunos e docentes de outros cursos, como Ciências Econômicas, Agronomia, Economia Doméstica, Geografia, Direito, Engenharia Agrícola e Ambiental, entre outros. Este caráter multidisciplinar é importante, considerando a diversidade e complexidade dos empreendimentos que são apoiados pelo programa. 
O processo de incubação de cooperativas populares pressupõe a junção de diversas áreas de conhecimento numa ação dialógica e participativa, inserida em espaços populares e comunitários, buscando contribuir para o desenvolvimento local e a geração de trabalho e renda. No campo da pesquisa, um conjunto substancial de artigos científicos e livros vem tratando de forma específica tanto do tema da economia solidária, como dos processos de incubação. Estudantes e docentes implicados no programa da ITCP-UFV dedicam parte dos trabalhos à reflexão desta prática, o que tem gerado diversas pesquisas que, ao longo desses anos, são apresentadas em congressos e eventos científicos, assim como se tornam fruto de publicações.

Dessa forma, as atividades de extensão são articuladas à pesquisa e ao desenvolvimento de tecnologias sociais adequadas aos empreendimentos econômicos populares. A sistematização metodológica possibilita a divulgação dos resultados alcançados e contribui para o desenvolvimento de políticas públicas no campo da Economia Solidária. Para a viabilização dessas ações e objetivos, a Incubadora conta com equipes de formadores responsáveis por assessorar e acompanhar empreendimentos, de acordo com segmentos produtivos, tais como: artesanato, agricultura familiar e reciclagem.

Visando a organização além das iniciativas coletivas, a ITCP trabalha também com o apoio aos Fóruns e Redes, em especial com o Fórum Mineiro de Economia Popular Solidária e a Rede Sudeste de ITCPs. O programa conta com equipe de comunicação responsável pela elaboração do Boletim Informativo e apresentações de enquetes teatrais, a partir de temáticas importantes para o trabalho desenvolvido.

A ITCP tem desenvolvido e buscado aperfeiçoar sua metodologia de incubação ao longo dos anos. É importante ressaltar que esse tipo de ação diferencia-se dos processos similares realizados em incubadoras de empresas. No caso dos empreendimentos econômicos solidários, as atividades são desenvolvidas com trabalhadores e trabalhadoras com baixa qualificação, pouco ou nenhum recurso para investimento, infraestrutura deficitária e acesso limitado às políticas públicas. Esses são elementos que caracterizam a economia dos setores populares e, por isso, demandam metodologias adequadas baseadas nos princípios da economia solidária e da educação popular. As fases compreendidas nesse processo pressupõem um trabalho de prática e reflexão constantes e são adaptadas às realidades de cada empreendimento, iniciativa solidária ou comunidade. Trata-se de uma metodologia dinâmica dividida pela ITCP-UFV em três etapas: aproximação, incubação, e desincubação.

As ações são realizadas de forma participativa e priorizam a autonomia e o empoderamento dos trabalhadores e trabalhadoras envolvidos nesses processos. As principais atividades realizadas com os empreendimentos econômicos solidários são: diagnóstico rápido participativo, planejamento 
estratégico, estudo de viabilidade econômico e associativo; orientação quanto à formalização; capacitação em gestão e economia solidária; apoio às estratégias de comercialização e divulgação de produtos; qualificação técnica e profissional; incentivo à organização de redes; e elaboração de projetos.

A etapa de aproximação representa o momento em que o empreendimento ou grupo popular entra em contato, a maioria pela primeira vez, com a temática da economia solidária. Trata-se de iniciativas econômicas e sociais que majoritariamente estão distantes da universidade não só por questões espaciais, mas também pela desigualdade social presente na sociedade brasileira. A ITCP-UFV, nessa fase, busca participar de espaços comunitários, visando divulgar a temática de trabalho e mobilizar iniciativas que estejam germinando ou caminhando com dificuldades. Esses espaços podem ser diversos, tais como Igrejas, Associações de Bairros, Sindicatos, organizações não-governamentais, Escolas, Centros de Referência de Assistência Social, Unidades Básicas de Saúde, entre outros. Essa etapa pode ocorrer por meio de "interações artísticas", visando à sensibilização das comunidades e a aproximação da ITCP, a partir de uma abordagem lúdica. Para iniciar os trabalhos de incubação, os empreendimentos devem apresentar um plano de ação do grupo e a atividade econômica em que estão inseridos. Da mesma forma, a Incubadora se apresenta, demonstrando as fases de Incubação, as responsabilidades envolvidas nessa parceria e a previsão de duração desse processo. Na sequência, é elaborado um plano de incubação, delimitando as responsabilidades e os papéis de cada ator. A partir disso, acontece a elaboração de um termo de compromisso construído junto com o grupo que deve conter o prazo de incubação e de sua renovação, de acordo com as fontes de recurso e os projetos disponíveis. Após esta fase, a ITCP desenvolve a etapa de Incubação.

A Incubação deve perpassar por três eixos estratégicos: econômico, solidário e político. O econômico relaciona-se aos aspectos de organização dos empreendimentos do ponto de vista da atividade de produção/ serviço a ser realizada, a viabilidade da mesma, o estudo de mercado, o plano de marketing, a qualificação técnica, a qualificação para gestão, a infraestrutura e as opções de formalização do grupo. No eixo solidário/ político, deve-se pensar a identidade do grupo, os acordos necessários para seu funcionamento, os espaços e instâncias de deliberação, os processos de autogestão, de decisão coletiva e participação, interação com a comunidade e intercooperação. Nessa fase, também estão previstos a formação nos princípios da economia solidária e o incentivo à participação em movimentos com essa temática. Nesse processo, um primeiro método interessante a ser utilizado é o Estudo de Viabilidade Econômica e Associativa em que os envolvidos podem compreender com clareza ações e metas para os empreendimentos sem deixar de lado os acordos associativos. A construção desse estudo será realizada de forma participativa e adaptada à realidade de cada empreendimento. 
Esta fase inclui também o momento de consolidação do empreendimento econômico solidário visando à ampliação de sua inserção econômica e social. É importante que a incubadora tenha, num segundo momento da Incubação, um papel muito mais de acompanhamento e assessoria do que de intervenção, visando uma maior autonomia e iniciativa do grupo, principalmente articulando ações em redes de diferentes naturezas e segmentos.

Por fim, a fase de desincubação leva em consideração o planejamento realizado inicialmente e suas avaliações periódicas. Os empreendimentos econômicos solidários serão desincubados depois de, no mínimo, três anos e, no máximo, cinco, sabendo que eles podem continuar a participar de ações pontuais promovidas pela Incubadora, assim como se almeja que os mesmos estejam articulados em redes e fóruns locais. Para isso, faz-se necessário construir um plano de desincubação com os indicadores e critérios favoráveis para o momento.

Ao longo de sua trajetória e depois de diversos espaços de avaliação da metodologia adotada no programa, percebeu-se que alguns pontos merecem ser repensados do ponto de vista metodológico. Nesse sentido, alguns pressupostos têm sido destacados na fase atual da Incubadora. Dentre eles, o programa se dedica a discutir aspectos importantes relacionados ao desenvolvimento local, redes de empreendimentos solidários e tecnologias sociais.

Dessa forma, é importante não considerar tais iniciativas isoladamente em um determinado território, mas apoiá-las na perspectiva do desenvolvimento local que, de acordo com Amaro (2009), pode ser considerado como um

[...] processo de satisfação de necessidades e de melhoria das condições de vida de uma comunidade local, a partir essencialmente das suas capacidades, assumindo a comunidade o protagonismo principal nesse processo e segundo uma perspectiva integrada dos problemas e respostas (AMARO, 2009, p. 108).

Além disso, ITCP-UFV tem buscado desenvolver seus trabalhos de acordo com a metodologia de incubação de redes de economia solidária. Para França Filho e Cunha (2009; p. 225), "Uma rede de economia solidária implica na associação ou articulação de vários empreendimentos e/ou iniciativas de economia solidária com vistas à constituição de um circuito próprio de relações econômicas e de intercâmbios de experiências e saberes formativos".. Esta abordagem de trabalho tem por objetivo permitir a sustentabilidade dos empreendimentos e/ou iniciativas solidárias e fortalecer as potencialidades de um determinado território para promover seu desenvolvimento. Assim, tais redes podem ser vistas como uma estratégia complexa de cooperação para o desenvolvimento local. Incentiva-se a criação de espaços próprios de 
comercialização e produção dessas redes, criando uma nova modalidade de regulação econômica, supondo outro modo de funcionamento da economia real (FRANÇA FILHO \& CUNHA, 2009).

Nesse contexto, o fortalecimento da economia solidária e dos empreendimentos econômicos solidários pressupõe a construção de uma ambiência favorável para tal desenvolvimento. A ITCP-UFV tem papel importante nesse campo pois pode contribuir para promoção de inovações sociais e tecnológicas, segundo pressupostos participativos e populares.

Segundo Dagnino (2009), a “Tecnologia Social (TS) é o resultado da ação de um coletivo de produtores sobre determinado processo de trabalho engendrado pela propriedade coletiva dos meios de produção, pelo controle autogestionário e pela cooperação voluntária e participativa”. Nessa perspectiva, é possível perceber que a TS é o resultado da ação de um ator social sobre um processo de trabalho por ele controlado em função das características do contexto socioeconômico, do acordo social e do ambiente produtivo. Esse ator é capaz de provocar uma alteração nesse processo no sentido de reduzir o tempo necessário à fabricação de um dado produto e de fazer com que a produção resultante seja dividida de acordo com seu interesse (DAGNINO, 2009).

Dessa forma, a ITCP-UFV desenvolve suas ações buscando articular ensino, pesquisa e extensão, em consonância com os pilares da universidade. Mais do que isso, desempenha um importante papel social e contribui de forma efetiva para a organização da economia solidária na região. Mesmo com diversos níveis de dificuldades, a busca por repensar a sua prática e aperfeiçoá-la consiste num ideal sempre perseguido. Em resumo, os principais resultados alcançados ao longo dos 10 anos de atuação do programa são: fortalecimento da economia solidária na Zona da Mata de Minas Gerais; consolidação de empreendimentos econômicos solidários, possibilitando a geração de trabalho e renda; divulgação e organização do movimento de economia solidária.

\section{Considerações finais}

O aumento da visibilidade da economia solidária no país foi acompanhado pelo crescimento de iniciativas inscritas nas universidades brasileiras direcionadas a essa temática, especialmente no campo da extensão universitária. Apesar de muitos desafios, fica claro que a consolidação do fomento aos empreendimentos econômicos no país tem, em parte, o apoio de instituições de ensino superior que trabalham no desenvolvimento metodológico e de inovação nesse campo.

A ITCP-UFV faz parte desse processo e, ao longo de seus 10 anos, busca desempenhar ações principalmente na Zona da Mata Mineira, envolvendo diversos segmentos econômicos. Os principais resultados 
alcançados envolvem a formação de estudantes nesse campo, a realização de ações de extensão baseadas em pressupostos dialógicos, desenvolvimento de pesquisas e avanços metodológicos.

O caráter multidisciplinar é uma característica do programa e representa sua maior riqueza. A interação dos conhecimentos acadêmicos com os saberes populares a partir de uma lógica horizontalizada determina a opção da ITCP por construir junto com os setores populares alternativas solidárias, sustentáveis e justas. Como espaço propício para reflexão crítica, programas como esses ainda merecem mais visibilidade e apoio. Os recursos para o desenvolvimento das ações geralmente são disponibilizados anualmente. No entanto, como fica claro ao longo desse artigo, o processo de incubação é contínuo e, muitas vezes, as dificuldades financeiras interrompem atividades em curso, causando resultados negativos. Parte das críticas direcionadas às Incubadoras ancora-se nesse tipo de fragilidade. Ao reconhecer seu potencial e papel fundamental numa conjuntura mais ampla no cenário brasileiro, espera-se que a extensão universitária, especialmente das Incubadoras, possa ser reconhecida, recebendo incentivos adequados à sua prática.

\section{Agradecimentos}

Agradeço aos alunos, alunas, professores, professoras, funcionários e funcionárias que ao longo desses 10 anos fizeram parte da trajetória da ITCP-UFV. Registro também meu agradecimento especial aos trabalhadores e trabalhadoras que confiaram no trabalho desenvolvido e contribuíram para o crescimento desse projeto. Agradeço às instituições financiadoras, à Pró-Reitoria de Extensão e Cultura e ao Departamento de Economia Rural.

\section{Referências Bibliográficas}

AMARO, R.R. Desenvolvimento local. In: CATTANI, A.D.; LAVILLE, J.; HESPANHA, P. (Orgs.). Dicionário Internacional da Outra economia. Coimbra: Altamira, 2009.

CORAGGIO,J.L. Una perspectiva alternativa para la economia social: de la economía popular a la economía del trabajo. In: CORAGGIO, J.L. La economía social desde la periferia: contribuiciones latinoamericanas. Buenos Aires: Altamira, 2007.

CUNHA, G.C.; SANTOS, A.M. Economia solidária e pesquisa em ciências sociais: desafios epistemológicos e metodológicos. In: HESPANHA, P.; SANTOS, A.M. (Orgs.). Economia solidária: questões teóricas e epistemológicas. Coimbra: Altamira, 2011. 
DAGNINO, R. Tecnologia Social. In: CATTANI, A.D.; LAVILLE, J.; HESPANHA, P. (Orgs.) Dicionário Internacional da Outra economia. Coimbra: Altamira, 2009.

FERREIRA, E. A cooperação no MST: a luta pela gestão coletiva dos meios de produção. In: SINGER, P.; SOUZA, A.R. (Orgs.) A economia solidária no Brasil: a autogestão como resposta ao desemprego. São Paulo: Contexto, 2003.

FRANÇA FILHO, G.C.; CUNHA, E.V. Incubação de redes de economia solidária. In: CATTANI, A.D.; LAVILLE, J.; HESPANHA, Pedro (Orgs.) Dicionário Internacional da Outra economia. Coimbra: Altamira, 2009.

FRANÇA FILHO, G.C. Políticas públicas de economia solidária no Brasil. In: FRANÇA FILHO, G.C.; LAVILLE, J.; MEDEIROS, A.; MAGNEN, J. Ação pública e economia solidária: uma perspectiva internacional. Porto Alegre: Editora da UFRGS, 2006.

GAIGER, L.I. Os caminhos da economia solidária no Rio Grande do Sul. In: SINGER, P.; SOUZA, A.R. (Orgs.) A economia solidária no Brasil: a autogestão como resposta ao desemprego. São Paulo: Contexto, 2003a.

GAIGER, L.I. La economia solidaria y el capitalismo en la perspectiva de las transiciones históricas. In: CORAGGIO, J.L. La economía social desde la periferia: contribuiciones latinoamericanas. Buenos Aires: Altamira, 2007.

GUIMARÃES, G. Incubadoras de Cooperativas Populares: contribuição para um modelo alternativo de geração de trabalho e renda. In: SINGER, P.; SOUZA, A.R. (Orgs.) A economia solidária no Brasil: a autogestão como resposta ao desemprego. São Paulo: Contexto, 2003.

LAVILLE, J. Ação pública e economia solidária na França. In: FRANÇA FILHO, G.C.; LAVILLE, J.; MEDEIROS, A.; MAGNEN, J. Ação pública e economia solidária: uma perspectiva internacional.Porto Alegre: Editora da UFRGS, 2006.

LÉVESQUE, B. Sociologia econômica. In: CATTANI, A.D.; LAVILLE, J.; HESPANHA, P. (Orgs.). Dicionário internacional da outra economia. Coimbra: Altamira, 2009.

LIMA, J.C. Cooperativas, trabalho associado, autogestão e economia solidária: a constituição do campo de pesquisa no Brasil. In: GEORGES, I.P.H.; LEITE, M.P. (Orgs.). Novas configurações do trabalho e economia solidária. São Paulo: Annablume, 2009.

MAGALHÃES, R.S.; TODESCHINI, R. Sindicalismo e economia solidária: reflexões sobre o projeto da CUT. In: SINGER, P.; SOUZA, A.R. (Orgs.) A economia solidária no Brasil: a autogestão como resposta ao desemprego. São Paulo: Contexto, 2003. 
NAKANO, M. Anteag: a autogestão como marca. In: SINGER, P.; SOUZA, A.R. (Orgs.) A economia solidária no Brasil: a autogestão como resposta ao desemprego. São Paulo: Contexto, 2003.

ODA, N.T. Sindicato e cooperativismo: os metalúrgicos do ABC e a Unisol Cooperativas. In: SINGER, P.; SOUZA, A.R. (Orgs.) A economia solidária no Brasil: a autogestão como resposta ao desemprego. São Paulo: Contexto, 2003.

PINTO, J.R.L. Economia solidária. De volta à arte da associação. Porto Alegre: Editora da UFRGS, 2006.

POCHMANN, M. Proteção social na periferia do capitalismo: considerações sobre o Brasil. São Paulo em perspectiva, São Paulo, v.18, n.2, p.3-16,2004.

POCHMANN, M. Posibilidades y limites de la economía solidaria latinoamericana. In: CORAGGIO, J.L.La economía social desde la periferia: contribuiciones latinoamericanas. Buenos Aires: Altamira, 2007.

QUIJANO, A. Sistemas alternativos de produção? In: SANTOS, B.S. (Org.). Produzir para viver: os caminhos da produção não capitalista. Rio de Janeiro: Civilização Brasileira, 2002.

SANTOS, B.S.; RODRÍGUEZ, C. Introdução: para ampliar o cânone da produção. In: SANTOS, B.S. (org.).Produzir para viver: os caminhos da produção não capitalista. Rio de Janeiro: Civilização Brasileira, 2002.

SINGER, P. A recente ressurreição da economia solidária no Brasil. In: SANTOS, B.S. (Org.). Produzir para viver: os caminhos da produção não capitalista. Rio de Janeiro: Civilização Brasileira, 2002.

SINGER, P. Economia solidária: um modo de produção e distribuição. In: SINGER, P.; SOUZA, A.R. (Orgs.) A economia solidária no Brasil: a autogestão como resposta ao desemprego. São Paulo: Contexto, 2003a.

SINGER, P. Incubadoras universitárias de cooperativas: um relato a partir da experiência da USP. In: SINGER, P.; SOUZA, A.R. (orgs.) A economia solidária no Brasil: a autogestão como resposta ao desemprego. São Paulo: Contexto, 2003b.

SINGER, P. In: Economía solidaria. Um modo de produccíon y distribuición. CORAGGIO, J.L. La economia social desde la periferia: contribuiciones latinoamericanas. Buenos Aires: Altamira, 2007.

TIRIBA, L. Pedagogia(s) de la producción: havia donde camina la economia popular? In: CORAGGIO, J.L. La economia social desde la periferia: contribuiciones latinoamericanas. Buenos Aires: Altamira, 2007.

VIVERET, P. Altermundialização. In: CATTANI, A.D.; LAVILLE, J.; HESPANHA, P. Dicionário internacional da outra economia. Coimbra: Altamira, 2009. p.11-15. 